\title{
HUBUNGAN SENAM NIFAS DENGAN PENURUNAN INVOLUSI UTERI PADA IBU POST PARTUM HARI KE 1-3 DI RSIA CICIK PADANG TAHUN 2016
}

\author{
Syaflindawati ${ }^{1}$, Dwi Putri Ayuning ${ }^{2}$ \\ Syaflindawati ${ }^{1}$ : STIKes Ranah Minang Padang, Parak Gadang 25123, Indonesia \\ Email: Syaflindawati.ramin@gmail.com
}

\begin{abstract}
ABSTRAK
Penyebab kematian ibu di Indonesia meliputi penyebab obstetri langsung yaitu perdarahan (28\%), preeklamsi/eklamsi (24\%), infeksi (11\%), sedangkan penyebab tidak langsung adalah trauma obstetri (5\%) dan lain- lain (11\%). Diperkirakan 60\% kematian ibu terjadi setelah kehamilan dan 50\% kematian masa nifas terjadi dalam 24 jam pertama, dimana penyebab utamanya adalah perdarahan pasca persalinan. Berdasarkan penyebab terjadi perdarahan adalah atonia uteri (50-60\%), retensio plasenta (16-17\%), sisa plasenta (23-24\%), laserasi jalan lahir (4-5\%), kelainan darah (0,5-0,8\%). Tujuan penelitian ini adalah untuk mengetahui hubungan antara senam nifas dengan penurunan involusi uteri pada ibu post partum hari ke 1-3 di RSIA CICIK Padang tahun 2016.

Jenis penelitian adalah analitik dengan desain cross sectional study yang dilakukan di RSIA CICIK Padang pada tahun 2016, dimana variabel dependentnya yaitu senam nifas dan variabel independentnya involusi uteri. Populasinya adalah semua ibu post partum yang bersalin di RSIA CICIK Padang pada bulan Mei-Juli yang berjumlah 167 orang dengan jumlah sampel 63 orang dengan teknik pengambilan sampel secara accidental sampling. Data dikumpulkan menggunakan kuesioner dan lembaran observasi. Data dianalisis secara univariat dan bivariat dengan menggunakan uji statistik chi-square.

Hasil penelitian didapatkan $65,1 \%$ ibu post partum melakukan senam nifas, $74,6 \%$ ibu post partum dengan penurunan involusi uteri yang cepat dan uji hipotesis didapatkan ada hubungan yang senam nifas dengan penurunan involusi uteri pada ibu post partum hari ke 1-3 di RSIA CICIK Padang tahun 2016.

Dapat disimpulkan bahwa senam nifas dapat mempengaruhi penurunan involusi uteri ibu post partum. Implikasi dari hasil penelitian ini yakni untuk mempercepat penurunan involusi uteri dapat dilakukan dengan senam nifas. Diharapkan hasil penelitian ini dapat dijadikan sebagai informasi bagi RSIA CICIK Padang dalam meningkatkan pelayanannya.
\end{abstract}

Kata Kunci $\quad$ : Senam Nifas, Post partum dan Penurunan Involusi Uteri

\section{ABSTRACT}

Causes of maternal mortality in Indonesia include the causes of obstetric directly ie bleeding (28\%), preeclampsia / eclampsia (24\%), infection (11\%), while the indirect cause is trauma obstetrics (5\%) and others (11\%). An estimated $60 \%$ of maternal deaths occur after pregnancy and 50\% of deaths during childbirth occur in the first 24 hours, which is the main cause of postpartum hemorrhage. Based on the cause of the bleeding is atonic (50-60\%), retained placenta (16-17\%), retained placenta (23-24\%), lacerations of the birth canal (4-5\%), blood disorders $(0.5$ to $0,8 \%)$. The purpose of this study was to determine the relationship between postpartum gymnastics with decreased uterine involution post partum mothers day to 1-3 in RSIA cicik Padang in 2016. This type of research is analytic design with cross sectional study conducted in RSIA CICIK Padang in 2016, where the variable dependentnya namely gymnastics parturition and variable independentnya is uterine involution. The population is all post partum mothers who give birth at RSIA CICIK Padang in May-July of 167 people with a total sample of 63 people and sample collection technique is by accidental sampling. Data were collected using questionnaires and observation sheets. Data was analyzed by univariate and bivariate using Chi-square test.The result showed $65.1 \%$ post partum mothers who do gymnastics parturition, $74.6 \%$ of mothers with post partum uterine involution rapid decline and the results of testing the hypothesis that Ha received is marked with $p$ value $=0.000(p<0.05)$ were means the presence of a significant relationship between postpartum gymnastics with decreased uterine involution post partum mothers day to 1-3 in RSIA CICIK Padang in 2016. It can be concluded that exercise can affect post-partum uterine involution decrease post partum mothers. The implication of this study which is to accelerate the decline of uterine involution can be done with gymnastics parturition. We hope this research can be used as information for RSIA cicik Padang in improving its services.

Keywords: Gymnastics Parturition, Post Partum and Decrease In uterine Involution 


\section{PENDAHULUAN}

Masa nifas merupakan masa yang rawan karena ada beberapa risiko yang mungkin terjadi pada masa itu, antara lain : anemia, pre eklampsia/ eklampsia, perdarahan post partum, depresi masa nifas, dan infeksi masa nifas. Menurut data,diantara resiko tersebut ada dua yang paling sering mengakibatkan kematian pada ibu nifas, yakni infeksi dan perdarahan. World Health Organization menyebutkan bahwa angka kematian ibu (AKI) di negara berkembang masih tinggi 500 per 100.000 kelahiran hidup. Berdasarkan data World Health Organization (WHO) dinegara berkembang bahwa jumlah kematian ibu dalam masa kehamilan, persalinan, dan masa nifas tahun 2009 sebanyak 2650 orang (WHO, 2009).

Kematian ibu (maternal death) menurut definisi WHO adalah kematian selama kehamilan atau dalam periode 42 hari setelah berakhirnya kehamilan, akibat semua sebab yang terkait dengan atau diperberat oleh kehamilan atau penanganannya, tetapi bukan disebabkan oleh kecelakaan/cedera. Penyebab utama kematian ibu berhubungan dengan komplikasi obstetrik selama masa kehamilan, persalinan dan masa nifas (post-partum) adalah Mayoritas penyebab kematian ibu.Angka Kematian Ibu (AKI) masih sangat tinggi di Indonesia. Setiap tahun, sekitar 20.000 ibu di Indonesia meninggal akibat komplikasi kehamilan atau persalinan. Sebanyak 259 ibu meninggal dunia pada setiap 100.000 kelahiran hidup. Angka itu lebih dari sepuluh kali AKI Malaysia (19) dan Sri Lanka (24). Target Pemerintah adalah menurunkan angka kematian ibu menjadi 102 per 100.000 kelahiran hidup pada tahun 2015 (Dianani, 2008).

Angka Kematian Ibu (AKI) di Indonesia masih termasuk yang tinggi dibandingkan negaranegara di asia misalnya Thailand dengan AKI 130/100.000 KH. Data SDKI tahun 2007 mencatat AKI di Indonesia mencapai 228 per 100.000 Kelahiran Hidup (KH). Walaupun angka ini dipandang mengalami perbaikan dibanding tahun tahun sebelumnya, Target Millenium Development Goals (MDGs)5 yaitu menurunkan AKI menjadi 102/100.000 (KH) pada tahun 2015 masih memerlukan upaya khusus dan kerja keras dari seluruh pihak baik Pemerintah, sektor swasta maupun masyarakat. AKI yang tinggi menunjukkan rawannya derajat kesehatan ibu (SDKI, 2009).

Penyebab kematian ibu di Indonesia meliputi penyebab obstetri langsung yaitu perdarahan (28\%), preeklamsi/eklamsi (24\%), infeksi $(11 \%)$, sedangkan penyebab tidak langsung adalah trauma obstetri $(5 \%)$ dan lain- lain (11\%).Diperkirakan $60 \%$ kematian ibu terjadi setelah kehamilan dan $50 \%$ kematian masa nifas terjadi dalam 24 jam pertama, dimana penyebab utamanya adalah perdarahan pasca persalinan.Berdasarkan penyebab terjadi perdarahan adalah atonia uteri (50-60\%), retensio plasenta (16-17\%), sisa plasenta (23-24\%), laserasi jalan lahir (4-5\%), kelainan darah (0,5$0,8 \%$ ). Faktor predisposisi terjadinya atonia uteri adalah uterus tidak berkontraksi, lembek, terlalu regang dan besar, kelainan pada uterus seperti mioma uteri dan solusio plasenta. Masa nifas adalah masa sesudah persalinan dan kelahiran bayi, plasenta, serta selaput yang diperlukan untuk memulihkan kembali organ kandungan seperti sebelum hamil dengan waktu kurang lebih 6 minggu. Pada masa nifas akan mengalami perubahan baik fisik maupun psikis. Perubahan fisik meliputi ligamen - ligamen bersifat lembut dan kendor, otot-otot tegang, uterus membesar, postur tubuh berubah sebagai kompensasi terhadap perubahan berat badan pada masa hamil(Siswono, 2005).

Di Provinsi Sumatera barat, jumlah kematiann ibu sebanyak 118 orang, meningkat dibanding tahun sebelumnya, dimana jumlah tertinggi adalah di Kota Padang sebanyak 16 orang dengan kasus terbanyak yaitu komplikasi nifas. Salah satu komplikasi nifas adalah proses involusi yang tidak berjalan dengan baik, yang disebut sub involusi yang akan menyebabkan perdarahan dan kematian ibu (Dinkes, 2015).

Cara Untuk menurunkan angka morbiditas pada masa post partum selain mobilisasi dini salah satu cara untuk mempercepat involusi uterus yaitu dengan melakukan senam nifas yang bertujuan merangsang otot-otot rahim agar berfungsi secara optimal sehingga diharapkan tidak terjadi perdarahan post partum dan mengembalikan rahim pada posisi semula. Manfaat senam nifas adalah memulihkan kembali kekuatan otot dasar panggul, mengencangkan otot-otot dinding perut dan perineum, membentuk sikap tubuh yang baik dan mencegah terjadinya komplikasi. Komplikasi yang dapat dicegah sedini mungkin dengan melaksanakan senam nifas adalah perdarahan post partum. Saat melaksanakan senam nifas terjadi kontraksi otot - otot perut yang akan membantu proses involusi. Pada kenyataannya banyak ibu nifas yang tidak melakukan senam nifas karena ada tiga alasan. Pertama, karena tidak tahu bagaimana senam nifas. Kedua, karena terlalu bahagia dan yang dipikirkan hanya si kecil. Ketiga, karena alasan sakit. Senam nifas sebaiknya dilakukan dalam waktu 24 jam setelah melahirkan, secara teratur setiap hari. Setelah 6 jam persalinan normal atau 8 jam setelah operasi sesar, ibu sudah boleh melakukan mobilisasi dini, termasuk senam nifas. Melakukan senam nifas akan mempengaruhi kebutuhan otot terhadap oksigen yang mana kebutuhan akan meningkat, berarti memerlukan aliran darah yang kuat seperti otot rahim. Dengan dilakukan senam nifas akan merangsang kontraksi rahim, sehingga kontraksi uterus akan semakin baik, pengeluaran 
lokia akan lancar yang akan berpengaruh terhadap proses involusi rahim (Sjaharudin,2006).

Dari hasil penelitian Masruroh (2012), menunjukan bahwa pengaruh senam nifas dengan penurunan tinggi fundus uteri maka diharapkan pada Institusi dan petugas kesehatan selama ibu berada di puskesmas. Lalu diberikan buku panduan melaksanakan senam nifas lanjutan untuk di rumah dan jadwal pelaksanaan senam yang sesuai dengan ketentuan. Untuk mengefektifkan senam bisa dilibatkan anggota keluarga yang terdekat sehingga bisa mengingatkan kepada ibu post partum dalam pelaksanaan senam nifas.

Bahadoran (2006) mmenyatakan bahwa senam nifas mempengaruhi aspek fisik guna meningkatkan kualitas hidup ibu post partum. Terdapat pengaruh yang signifikan pada kelompok ibu yang melakukan latihan fisik terhadap kesejahteraan fisik ibu post partum. Latihan fisik teratur merupakan faktor penting untuk menjaga kesehata fisik juga mempertahankan fungsi dan kekuatan otot secara maksimal termasuk organ reproduksi.

RSIA CICIK PADANG merupakan Rumah Sakit yang memberikan pelayanan rawat inap kebidanan dengan salah satu program unggulannya yaitu senam nifas yang dilakukan setelah 24 jam pertama pasca bersalin. Jumlah persalinan yang ada dari bulan Januari sampai bulan Desember 2015 yaitu 730 pasien, dengan persalinan normal 161 persalinan dan persalinan dengan tindakan 569 persalinan. Persalinan normal ditolong oleh dokter atau bidan sedangkan persalinan tindakan ditolong oleh dokter. Data terbaru yang diperoleh dari RSIA CICIK Padang pada bulan Januari-Maret 2016 jumlah persalinan yaitu sekitar 179 pasien. Pasien dengan persalinan normal berjumlah 81 pasien dan 98 pasien dengan persalinan tindakan. Dari 81 pasien dengan persalinan normal terdapat 31 pasien dengan kasus perdarahan, dimana 19 dari 31 pasien tersebut tidak melakukan senam nifas(Rekam Medis RSIA CICIK).

Hasil wawancara dengan 2 bidan pada tanggal 23 Februari 2016 pada bagian kebidanan menyatakan bahwa pasien yang dirawatsetelah 1 hari post partum belum adanya dilakukan senam nifas. Dan hasilwawancara dengan 6 pasien post partum pada tanggal 23 Februari 2016 di ruang rawatan, mereka mengatakan masih takut untuk melakukan banyak gerakan karena 2 dari 6 ibu merupakan pengalaman pertama dalam menjalanimasa nifas dan untuk mengecilkan perut memakai stagen dengan pemberitahuan dari keluarga atau orang terdekat yang diyakini bahwa dengan pemakaian stagen bisa mengembalikan perut yang mengalami peregangan.Berdasarkan uraian diatas peneliti merasa tertarik untuk melakukan penelitian mengenai "hubungan senam nifas dengan penurunan involusi uteri pada ibu post partum hari ke 1-3 di RSIA CICIK PADANG tahun 2016.

\section{METODE PENELITIAN}

Penelitian ini bersifat analitik dengan desain cross sectional yaitu suatu penelitian untuk mempelajari dinamika korelasi antara faktor-faktor resiko dengan efek, dengan cara pendekatan, observasi atau pengumpulan data sekaligus (Notoadmodjo, 2010).

1. Populasi

Populasi dalam penelitian ini adalah semua ibu post partumyang bersalin di RSIA CICIK Padang pada bulan Mei-Juli yang berjumlah 167 orang.

2. Sampel

Sampel adalah sebagian yang diambil dari keseluruhan objek yang diteliti dan dianggap yang mewakili seluruh populasi (Arikunto, 2009). Dengan kriteria sebagai berikut :

Kriteria Eksklusi :

3. Ibu post partum yang selama waktu penelitian meninggalkan wilayah Kota Padang

4. Ibu post partum yang selama penelitian mengalami komplikasi post partum.

Tempat yang digunakan untuk melaksanakan penelitian tentang hubungan sinam nifas dengan penurunan involusi uteri pada ibu post partum hari ke 1-3 di RSIA CICIK Padang Tahun 2016. Penelitian ini dilakukan pada bulan Oktober 2016.

\section{HASIL PENELITIAN}

Dari hasil penelitian yang telah dilakukan tentang hubungan antara senam nifas dengan penurunan involusi uteri pada ibu post partum hari ke 1-3 di RSIA CICIK Padangdengan jumlah sampel sebanyak 63 orang, didapatkan hasil penelitian sebagai berikut:

1. Penurunan Involusi Uteri

Tabel.1 Distribusi Frekuensi Responden Berdasarkan Penurunan Involusi Uteri pada Ibu Post Partum Hari ke 1-3 di RSIA CICIK Padang Tahun 2016

\begin{tabular}{|c|c|c|}
\hline Penurunan Involusi Uteri & $f$ & $\%$ \\
\hline Cepat & 47 & 74,6 \\
\hline Lambat & 16 & 25,4 \\
\hline Jumlah & 63 & 100 \\
\hline
\end{tabular}

Berdasarkan tabel 1 terlihat bahwa lebih dari separuh yaitu $47(74,6 \%)$ orangibu post partum dengan penurunan involusi uteri yang cepat di RSIA CICIK Padang Tahun 2016. 
2. Senam Nifas

Tabel 2. Distribusi FrekuensiResponden Berdasarkan Senam Nifas di RSIA CICIK Padang Tahun 2016

\begin{tabular}{ccc}
\hline Senam Nifas & $\boldsymbol{f}$ & $\mathbf{\%}$ \\
\hline Dilakukan & 41 & 65,1 \\
Tidak dilakukan & 22 & 34,9 \\
\hline Jumlah & $\mathbf{6 3}$ & $\mathbf{1 0 0}$ \\
\hline
\end{tabular}

Berdasarkan tabel 2 terlihat bahwa lebih dari separuh yaitu $41(65,1 \%)$ orang ibu post partum yang melakukan senam nifas di RSIA CICIK Padang Tahun 2016.

\section{Analisa Bivariat}

3. Hubungan senam nifas dengan penurunan involusi uteri

Tabel 3. Hubungan Senam Nifas dengan Penurunan Involusi Uteri di RSIA CICIK Padang Tahun 2016

\begin{tabular}{|c|c|c|c|c|c|c|c|}
\hline \multirow[t]{3}{*}{ No. } & \multirow[t]{3}{*}{$\begin{array}{l}\text { Senam } \\
\text { Nifas }\end{array}$} & \multicolumn{4}{|c|}{$\begin{array}{c}\text { Penurunan Involusi } \\
\text { Uteri }\end{array}$} & \multirow{2}{*}{\multicolumn{2}{|c|}{ Jumlah }} \\
\hline & & \multicolumn{2}{|c|}{ Cepat } & \multicolumn{2}{|c|}{ Lambat } & & \\
\hline & & $f$ & $\%$ & $f$ & $\%$ & $f$ & $\%$ \\
\hline 1 & Dilakukan & 38 & 60,3 & 3 & 4,8 & 41 & 65,1 \\
\hline \multirow[t]{2}{*}{2} & $\begin{array}{c}\text { Tidak } \\
\text { dilakukan }\end{array}$ & 9 & 14,3 & 13 & 20,6 & 22 & 34,9 \\
\hline & Total & 47 & 100 & 16 & 100 & 63 & 100 \\
\hline
\end{tabular}

Berdasarkan tabel 3 dapat dilihat bahwa proporsi ibu post partum yang melakukan senam nifas dengan penurunan involusi uteri yang cepat $(60,3 \%)$ lebih banyak dibandingkan pada ibu post partum yang tidak melakukan senam nifas $(14,3 \%)$.

Secara statistik dengan uji Chi-Square menunjukkan $\mathrm{p}$ value $=0,000$ atau $\mathrm{p}<0.05$ yang berarti ada hubungan senam nifas dengan penurunan involusi uteri pada ibu post partum di RSIA CICIK Padang Tahun 2016.

\section{PEMBAHASAN}

\section{Analisa Univariat}

\section{Senam Nifas}

Berdasarkan hasil penelitian, didapatkan 41 $(65,1 \%)$ orangibu post partum yang melakukan senam nifas dan $22(34,9 \%)$ orang ibu yang tidak melakukan senam nifas di RSIA CICIK Padang Tahun 2016

Selama kehamilan dan persalinan ibu banyak mengalami perubahan fisik seperti dinding perut mengendur, longgarnya liang senggama dan otot dasar panggul. Untuk mengembalikan ke keadaan normal dan menjaga kesehatan agar tetap prima, senam nifas sangat baik dilakukan pada ibu setelah melahirkan.Senam nifas berupa gerakan-gerakan untuk mengencangkan otot, terutama otot-otot perut yang mengendur akibat kehamilan.

Umumya, para ibu pasca persalinan takut melakukan banyak gerakan. Sang ibu biasanya khawatir geraka-gerakan yang dilakukannya akan menimbulkan dampak yang tidak diinginkan. Padahal, apabila ibu bersalin melakukan ambulansi dini, itu bisa mempelancar terjadinya proses involusi uteri (kembalinya rahim ke bentuk semula). Salah satu aktivitas yang dianjurkan untuk dilakukan para ibu setelah persalinan adalah senam nifas. Senam ini dilakukan sejak hari pertama setelah melahirkan hingga hari ke sepuluh.Dalam pelaksanaannya, harus dilakukan secara bertahap, sistematis dan kontinyu (Nugroho, 2014).

Hasil penelitian ini hampir sama dengan penelitian yang telah dilakukan oleh Masruroh (2012) tentang hubungan senam nifas dengan kecepatan penurunan involusi uteri pada ibu nifas di Puskesmas Brebah Sleman Yogyakarta, dimana ditemukan $55,1 \%$ ibu post partum yang melakukan senam nifas.

Berdasarkan hasil penelitian di RSIA CICIK Padang, masih adanya ibu post partum yang tidak mau melakukan gerakan atau mobilisasi seperti senam nifas pasca bersalin hal ini terlihat pada proses penurunan involusi uteri ibu yang melakukan senam nifas lebih cepat dari pada yang tidak melakukan senam nifas. Pada ibu yang melakukan senam nifas pengeluaran locheanya lancar sehingga proses involusipun berjalan normal sedangkan pada ibu yang tidak melakukan senam nifas, banyak dari mereka yang mengeluh kembung dan bahkan ada yang lochea nya tidak keluar sama sekali.

\section{Penurunan Involusi Uteri}

Hasil penelitian yang dilakukan terhadap 63 orang ibu post partum, didapatkan $47(74,6 \%)$ orangibu yang mengalami penurunan involusi uteri dengan cepat dan $16(25,4 \%)$ orang ibu dengan penurunan involusi uteri yang lambat di RSIA CICIK Padang Tahun 2016.

Beberapa faktor yang mempengaruhi proses involusi uteri diantaranya yaitu : Gizi, mengatakandengan status gizi yang adekuat akan mempercepat pemulihan kesehatan ibu pasca bersalin dan pengembalian kekuatan otot-ototnya menjadi lebih cepat serta akan meningkatkan kualitas maupun kuantitas Air Susu ibu atau ASI. Disamping itu ibu pasca bersalin akan lebih mampu menghadapi serangan- serangan kuman sehingga tidak terjadi infeksi dalam nifas, mobilisasi dini adalah aktivitas segera yang dilakukan setelah beberapa jam dengan beranjak dari tempat tidur pada ibu dengan persalinan normal (Nugroho, 2014). 
Menurut Kenneth (2009), proses penurunan TFU dikatakan cepat jika pada hari pertama dan kedua nifas TFU $\geq 1$ jari bawah pusat dan pada hari ke-3 berada $\geq 3$ jari bawah pusat. Dikatakan normal jika pada hari pertana 1 jari dibawah pusat, dan pada hari ke 3 TFU 3 jari dibawah pusat.Tapi dikatakan lambat jika pada hari pertama dan kedua TFU berada $<1$ jari dibawah pusat, dan pada hari ke 3 TFU setinggi $<3$ jari dibawah pusat.

Hasil penelitian ini hampir sama dengan penelitian yang telah dilakukan oleh Azizah (2013) tentang hubungan antara senam nifas dengan perbedaan masa involusi uteri pada ibu nifas di RST Medan dimana ditemukan 50,2\% ibu post partum yang mengalami penurunan involusi uteri dengan cepat.

Analisa peneliti, cepat atau lambatnya penurunan involusi uteri pada ibu post partum di RSIA CICIK Padang, terlihat dari lembar observasi, dimana terjadinya penurunan involusi yang cepat pada ibu yang melakukan senam nifas dan penurunan involusi uteri yang lambat pada ibu yang tidak melakukan senam nifas.

\section{Analisa Bivariat}

\section{Hubungan Senam Nifas dengan Penurunan Involusi Uteri}

Berdasarkan hasil penelitian, didapatkan bahwa proporsi ibu post partum dengan penurunan involusi uteri yang lambat lebih banyak terdapat pada ibu yang tidak melakukan senam nifas (20,6\%)dibandingkan pada ibu yang melakukan senam nifas $(4,8 \%$.).

Secara statistik dengan uji Chi-Square menunjukkan $\mathrm{p}$ value $=0,000$ atau $\mathrm{p}<0.05 \mathrm{yang}$ berarti terdapatnya hubungan yang berarti antara senam nifas dengan penurunan involusi uteri pada ibu post partum hari ke 1-3 di RSIA CICIK Padang Tahun 2016.

Hasil penelitian ini sama dengan penelitian yang telah dilakukan oleh Nawati (2010) tentang hubungan senam nifas terhadap involusi uterus pada ibu post partum di RSUD Mayjen A. Thalib Kerinci, dimana ditemukan adanya hubungan antara senam nifas dengan involusi uterus.

Salah satu cara untuk mempercepat involusi uterus yaitu dengan melakukan senam nifas yang bertujuan merangsang otot-otot rahim agar berfungsi secara optimal sehingga diharapkan tidak terjadi perdarahan post partum dan mengembalikan rahim pada posisi semula. Manfaat senam nifas adalah memulihkan kembali kekuatan otot dasar panggul, mengencangkan otot-otot dinding perut dan perineum, membentuk sikap tubuh yang baik dan mencegah terjadinya komplikasi. Komplikasi yang dapat dicegah sedini mungkin dengan melaksanakan senam nifas adalah perdarahan post partum.
Saat melaksanakan senam nifas terjadi kontraksi otot-otot perut yang akan membantu proses involusi. Pada kenyataannya banyak ibu nifas yang tidak melakukan senam nifas karena ada tiga alasan. Pertama, karena tidak tahu bagaimana senam nifas. Kedua, karena terlalu bahagia dan yang dipikirkan hanya si kecil. Ketiga, karena alasan sakit. Senam nifas sebaiknya dilakukan dalam waktu 24 jam setelah melahirkan, secara teratur setiap hari. Setelah 6 jam persalinan normal atau 8 jam setelah operasi sesar, ibu sudah boleh melakukan mobilisasi dini, termasuk senam nifas. Melakukan senam nifas akan mempengaruhi kebutuhan otot terhadap oksigen yang mana kebutuhan akan meningkat, berarti memerlukan aliran darah yang kuat seperti otot rahim. Dengan dilakukan senam nifas akan merangsang kontraksi rahim, sehingga kontraksi uterus akan semakin baik, pengeluaran lokia akan lancar yang akan berpengaruh terhadap proses involusi rahim (Sjaharudin,2006).

Analisa peneliti, terdapatnya hubungan antara senam nifas dengan penurunan involusi uteri karena dengan melakukan senam nifas akan merangsang kontraksi rahim, sehingga kontraksi uterus akan semakin baik, pengeluaran lochea akan lancar yang akan berpengaruh terhadap proses penurunan involusi rahim.

\section{KESIMPULAN DAN SARAN}

\section{Kesimpulan}

Berdasarkan penelitian yang telah dilakukan tentang hubungan antara senam nifas dengan penurunan involusi uteri pada ibu post partum hari ke 1-3 di RSIA CICIK Padang, peneliti mendapatkan kesimpulan sebagai berikut :

1. Lebih dari separuh $(65,1 \%)$ ibu post partum melakukan senam nifas di RSIA CICIK Padang Tahun 2016.

2. Lebih dari separuh $(74,6 \%)$ ibu post partum dengan penurunan involusi uteri yang cepat di RSIA CICIK Padang Tahun 2016.

3. Terdapatnya hubungan antara senam nifas dengan penurunan involusi uteri pada ibu post partum hari ke 1-3 di RSIA CICIK Padang Tahun 2016.

\section{Saran}

Berdasarkan kesimpulan yang didapatkan dari hasil penelitian maka peneliti menyarankan :

1. Bagi Tempat Penelitian

Diharapkan hasil penelitian ini dapat dijadikan sebagai bahan informasi bagi RSIA CICIK Padang dalam memberikan motivasi kepada pasien post partum untuk melakukan senam nifas agar mempercepat penurunan involusi uteri.

2. Bagi Peneliti Berikutnya

Diharapkan kepada peneliti selanjutnya dapat melanjutkan penelitian ini dengan melihat faktor- 
faktor yang berpengaruh terhadap penurunan involusi uteri pada ibu post partum.

\section{DAFTAR PUSTAKA}

Alimul Hidayat, A. Aziz. 2007. Metode Penelitian Kebidanan teknik analisa data. Jakarta: Salemba Medika

Ambarwati. 2008. Asuhan Kebidanan (nifas).

Yogyakarta : Mitra Cendekia 2012. Pengaruh Pemberian Larutan Ekstrak Jeruk Nipis terhadap pembentukan plak gigi. Naskah Skripsi. Fakultas Kedokteran Universitas Diponegoro Semarang

Arikunto, S. 2009. Prosedur Penelitian Suatu Pendekatan Praktek. Edisi revisi VI. Jakarta: Rineka Cipta

Azizah. 2013. Perbedaan Masa Involusi Uteri dengan Senam Nifas. Jurnal Kesehatan (online), Diakses dari https://www.google.co.idjurnal+online tanggal 20 juli 2016 jam 19.00 wib

Bahadoran. 2006. Senam nifas mempengaruhi aspek fisik guna meningkatkan kualitas hidup ibu post partum. Jurnal Kesmas (online), Diakses dari

http://jurnal.fk.unand.ac.id/index.php/jka/articl e/view/111 tanggal 7 juli 2016 jam $13.00 \mathrm{wib}$

Brayshaw, E. 2007. Senam Hamil dan Nifas. Jakarta : Buku Kedokteran EGC 2008. Senam Hamil dan Nifas. Jakarta EGC

Bobak. 2005. Buku Ajar Keperawatan Maternitas edisi 4. Jakarta : EGC

Danuatmaja, B., dan Meiliasari, M. 2006. Persalinan Normal Tanpa Rasa Sakit. Jakarta : Puspa Swara

Dianani, ida, 2008. Gambaran involusi uteri pada ibu post partum. Jurnal Pendidikan Kesehatan (online) Diakses dari : http://ejournal.stikesppni.ac.id/index.php/JKS/article/view/223 tanggal 2 agustus 2016 jam $18.00 \mathrm{wib}$

Dinas Kesehatan (Dinkes), 2015

Jenny. 2006. Perawatan Masa Nifas Ibu dan Bayi. Jakarta: Sahabat Setia

Lawdewing, Patricia W. London, Marcia L dan Olds, Sally B. 2006. Asuhan keperawatan keperawatan Ibu-Bayi Baru Lahir. Jakarta : EGC

Leveno, Kenneth. 2009. Obstetric Williams Panduan Ringkas. Jakarta : EGC

Manuaba, I.B.G., I.A. Chandranita Manuaba, dan I.B.G. 2006. Pengantar Kuliah Obstetri. Jakarta: Buku Kedokteran EGC

Masruroh. 2012. Pengaruh senam nifas dengan penurunan tinggi fundus uteri. Skripsi Keperawatan (online) Diakses dari :
PENGARUHSENAMNIFASTERHADAPPE

NURUNANTINGGIFUNDUSUTERIPADAI

BUPOSTPARTUM tanggal 12 juni 2016 jam $15.00 \mathrm{wib}$

Mochtar, Rustam. 2007. Sinopsis Obstetri. Jakarta : EGC

Notoatmodjo, Soekidjo. 2010. Metodologi Penelitian Kesehatan. Jakarta: Rineka Cipta

Nugroho, Taufan. 2014. Buku Ajar Asuhan Kebidanan Nifas. Yogyakarta : Nuha Medika

Nurtiati. 2014. Pengaruh Senam Nifas terhadap penurunan tinggi Fundus Uteri pada ibu Post Partum. Jurnal keperawatan Maternitas (online). Diakses dari https://www.google.co.idFNASKAHPUBLIK ASI.pdf tanggal 20 juli 2016 jam 12.00 wib

Puspayanti. 2010. Pantangan Buat Ibu 40 Hari Pasca Persalinan (online). Diakses dari http://www.khasanah.com.id tanggal 11 Juni 2016 jaam 13.00 wib

Reeder, Martin dan Koniak-Griffin. 2011. Volume 2 keperawatan Maternitas Kesehatan Wanita, Bayi dan Keluarga Edisi 18. Jakarta : EGC

Rekam Medis RSIA CICIK Padang

Siswono,. 2005. Program ASI Eksklusif Hingga Bayi Usia Enam Bulan. Available at : http://www.mediaindo.co.id. (Akses 15 September 2016)

Sjaharuddin Harun, Idrus Alwi. Ifark Miokard Akut Tanpa Elevasi ST. In : Aru W. Sudoyo, Bambang Setiyohadi, Idrus Alwi, Marcellus Simadibrata K., Siti Setiati. 2006. Buku Ajar Ilmu Penyakit Dalam Jilid 3. Edisi IV. Jakarta : Pusat Penerbitan Ilmu Penyakit Dalam Fakultas Kedokteran Universitas Indonesia. P. 1626-32.

Surtati. 2010. Pengaruh senam nifas terhadap pemulihan fisik pada ibu post partum. Jurnal Kebidanan tiga (online). Diakses dari : https://www.scribd.com/doc/Pengaruh-SenamNifas-Terhadap-Kecepatan-Penurunan-TinggiFundus-Uteri-Pada-Ibu-Post-Partum tanggal 2 agustus 2016 jam $13.00 \mathrm{wib}$

Survey Demografi Kesehatan Indonesia (SDKI), 2009

World Health Organization (WHO) 